\title{
Civil engineering: fit for the future
}

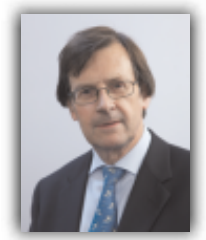

This is the inaugural address of David Balmforth, who became the 150th president of the Institution of Civil Engineers on 5 November 2014.

Today's infrastructure: the historic context

The Institution of Civil Engineers (ICE) is the oldest professional body for engineers, formed nearly 200 years ago by Thomas Telford and his colleagues, when they met in a coffee house in London to form a learned society for civil engineers (ICE, 2014a).

Then Britain was at the threshold of the industrial revolution - not an evolution but a revolution - that would ultimately shape the future of the world. How did those early engineers see their future, and how well prepared were they for the challenges that lay ahead? They came from all walks of life and, unlike today, many had no training or qualifications; yet they laid the foundations of the roads, the railways and the water supply systems on which our modern society now depends.

Their ingenuity and tenacity has been replicated in all subsequent generations, taking us from canals to motorways, inclined planes to high-speed rail, cottages to high-rise buildings and midden heaps to modern sanitation.

The profession, and the work that it delivers today, would have been beyond the imagination of those early engineers: railways running at over $400 \mathrm{~km} / \mathrm{h}$, a ship canal joining the Atlantic and Pacific

Oceans, and a bridge connecting Sweden to Denmark. How could they have foreseen the current pace of change, the globalisation of our business, and the demands of a society fuelled by the instant world of computing and the internet?

As well as wrestling with the embryonic principles of construction they had to convince wary investors, persuade uninterested politicians and accommodate a sceptical public that often treated their ideas as absurd (Figure 1).

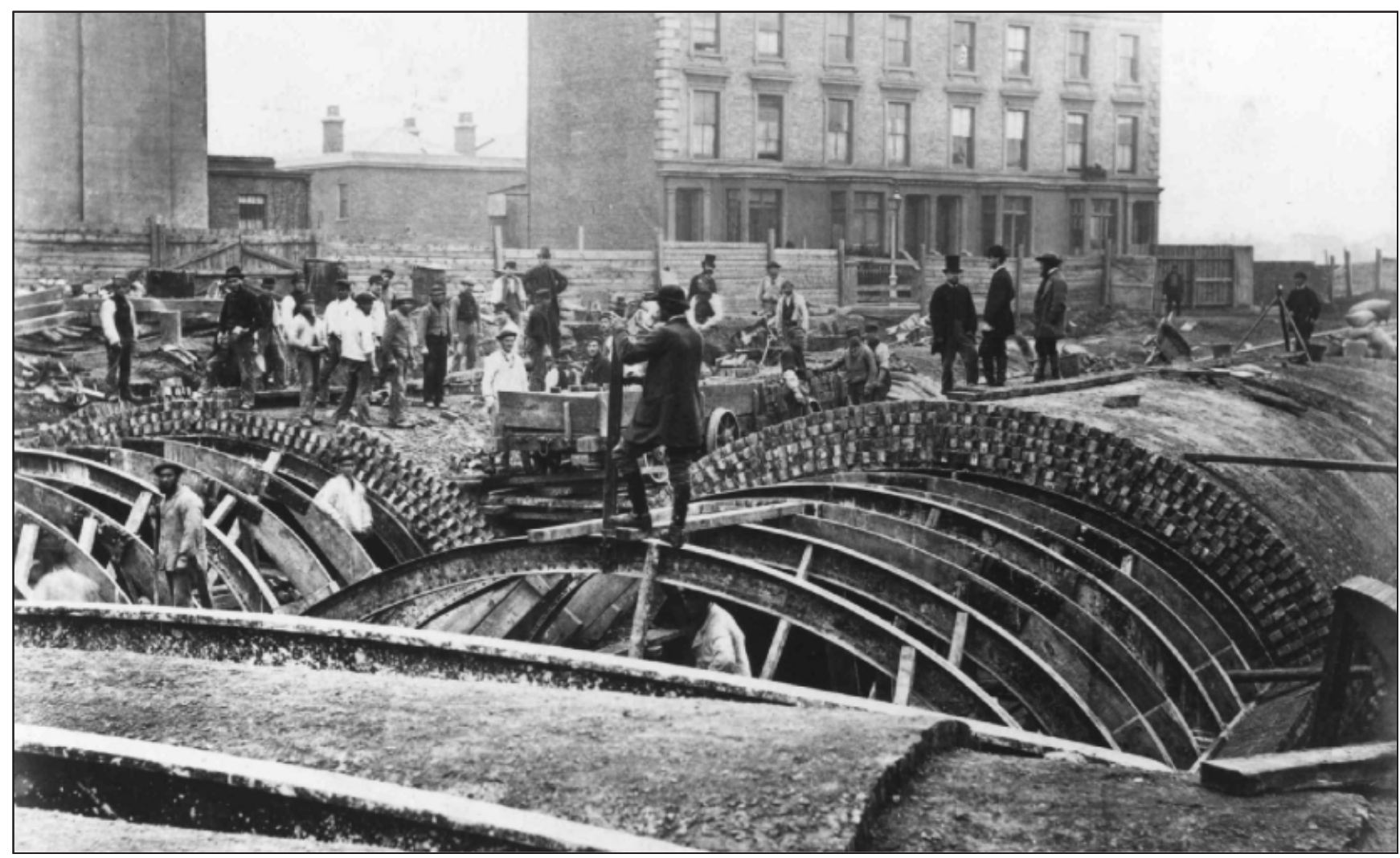

Figure 1. Early construction of London Underground - civil engineers need to continue stepping beyond their thresholds 


\section{PRESIDENTIAL ADDRESS:DAVID BALMFORTH}

\section{Infrastructure fragility}

The infrastructure that supports modern city living has evolved over many generations into a highly sophisticated system (Figure 2).

In New York alone infrastructure provides $450 \mathrm{GWh}$ of electricity each day to homes and businesses (NYISO, 2014: p. 34), and the Tokyo metro conveys $6 \cdot 2$ million passengers per day (Tokyo Metro, 2014). In London, almost $2400 \mathrm{Ml}$ of water are consumed per day (Mayor of London, 2011: p. 39) and a similar amount of sewage is collected and treated. Every day, $6000 \mathrm{~m}^{2}$ more office accommodation is brought on-line in Shanghai (Bloomberg, 2013).

Our cities are the powerhouse of the global economy. London, for example, delivers more than $20 \%$ of the UK's gross domestic product (ONS, 2014). However, in recent years we have not been short of examples that demonstrate the fragility of those cities and the infrastructure that supports them.

When hurricane Katrina hit the city of New Orleans in 2005 the immediate flooding led to cascading infrastructure collapse (Figure 3). Once the power supply failed, cash machines ceased to operate and people could no longer gain access to their money. Needing food they raided local grocery stores and this then led to widespread looting. New Orleans is a city in one of the most

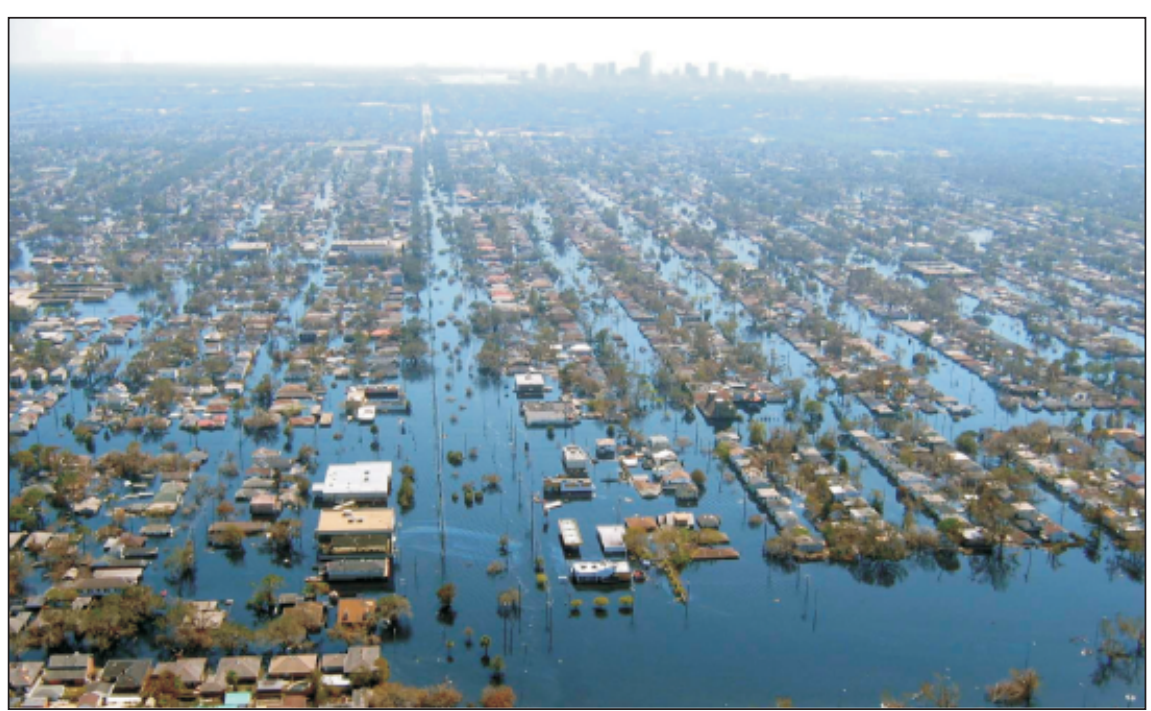

Figure 3. Fragility of infrastructure - society broke down in New Orleans after hurricane Katrina (by Commander Mark Moran, of the NOAA Aviation Weather Center, via Wikimedia Commons) advanced nations on earth, and yet it took only $8 \mathrm{~h}$ for society to collapse (BBC, 2005).

An earthquake in Christchurch in 2011 reduced the city centre to ruin (Rafferty, 2014); and closer to home, the UK floods of 2007, 2008, 2010 and $2013 / 2014$ have aptly demonstrated the vulnerability of society to the extremes of nature.

Our infrastructure has become ever more complex and interdependent. We

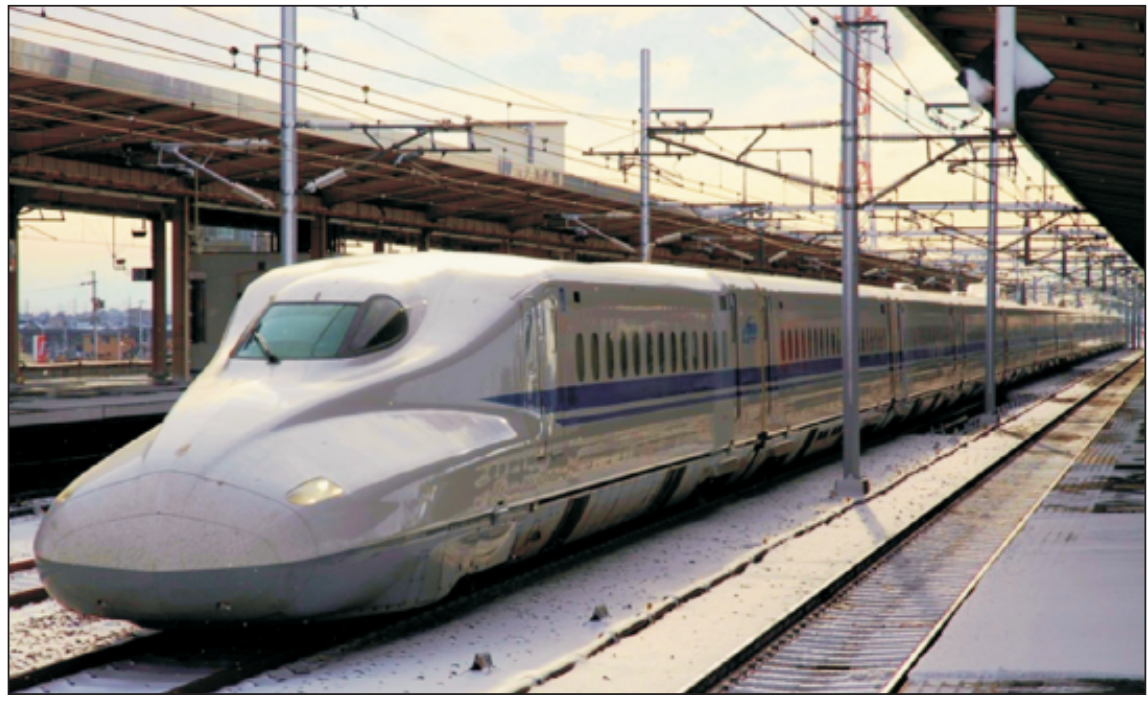

Figure 2. High-speed railway in Japan - an example of how modern infrastructure supports the global economy (by spaceaero2 (Own work) [GFDL (http://www.gnu.org/copyleft/fdl.html) or CC-BY-3.0 (http://creativecommons.org/licenses/by/3·0)], via Wikimedia Commons (http:// commons.wikimedia.org/wiki/File\%3AJR_central_N700series_Z0_gihu-hashima.jpg))

have rightly sought to improve the efficiency of infrastructure, but there is evidence that this been realised at the expense of redundancy.

Redundancy is important in providing resilience against failure. Equally, the drive for efficiency has diverted our attention away from the importance of planned maintenance. Indeed, ICE's State of the Nation: Infrastructure 2014 report (ICE, 2014b) questions if we have built new infrastructure before ensuring we can afford to maintain the infrastructure we already have.

Have we failed to understand properly the relationship between efficiency, redundancy and resilience? Have we lost sight of the central role that infrastructure plays in securing and sustaining society? And have we set our sights on understanding the future demands that the world will ask of us and of the infrastructure that we provide?

\section{Future infrastructure: shaping the world}

The global mega-trends that will impact on our future world are of such a scale that they stretch our ability to comprehend them. They test our capacity to imagine a future where prosperity and sustainability can work in harmony. 


\section{PRESIDENTIAL ADDRESS:DAVID BALMFORTH}

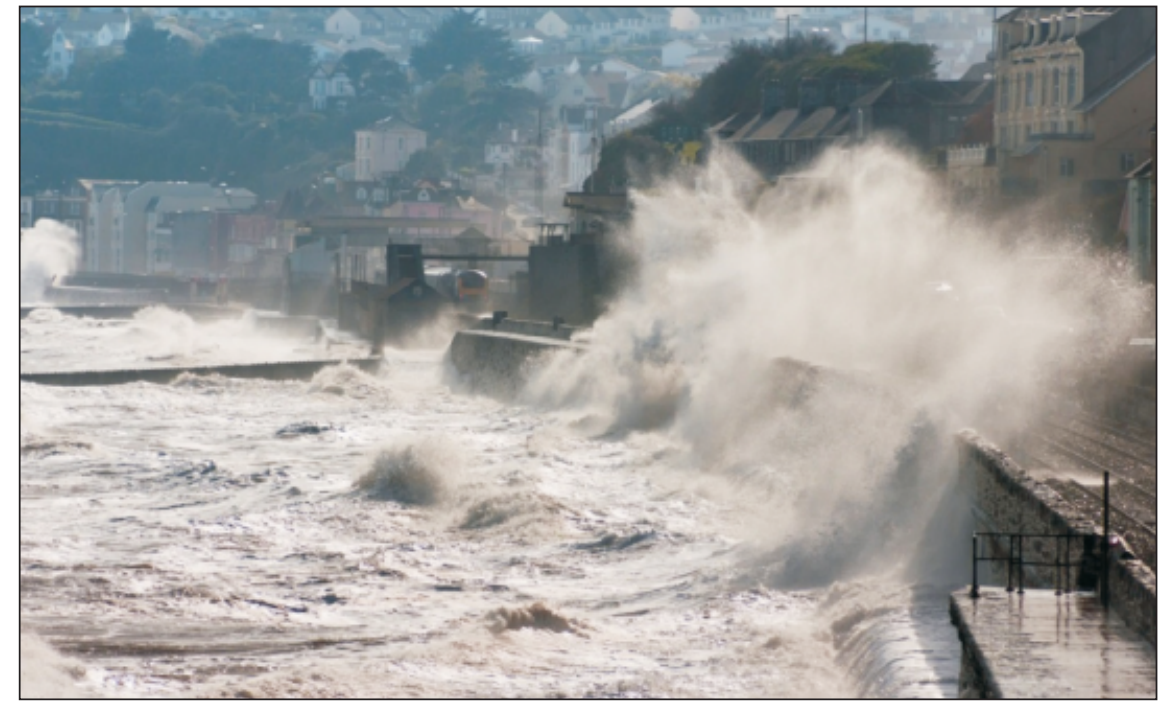

Figure 4. Resilient infrastructure - storm damage to the main railway in Devon, UK in 2014 showed how critical infrastructure is to sustaining local economies

- Climate change - by 2100 sea levels may have risen by up to $1 \mathrm{~m}$ around the world (Gregory, 2013). In the Bay of Bengal alone a sea level rise of just $400 \mathrm{~mm}$ would put $11 \%$ of

Bangladesh's land area under water, creating 7 to 10 million climate refugees (IPCC, 2007).

- Population growth - we will see the world's population grow to 11 billion by 2100 (based on figures from the United Nations Department of Economic and Social Affairs, Population Division (2014)). This will mainly be in the large cities of the world and mostly in poorer communities. Even in the developed world, cities will struggle to cope with population growth, leading to the rapid expansion of slum communities inadequately served with water, energy and sanitation.

- Resource depletion - without a radical change in direction some key materials will no longer be generally available and water resources may be inadequate to support global food production.

- Economic instability - inadequate infrastructure, especially housing, water, sanitation and transport will stress some communities beyond the point at which they are viable, leading to economic and social collapse. Indeed, civil unrest and damage resulting from population migration and natural disasters could have more of an impact on global wellbeing than wars or terrorism (Figure 4)

Governments, individually and collectively, have been slow to react, often because their planning horizons are short and public interest is even shorter. But civil engineers do not work to short time frames. We build infrastructure today to last for many generations.

Today we stand on a new threshold for change, in the same way as our forebears nearly 200 years ago. Can we rise to the challenge in the same way that our predecessors did in the past and shape a world that is fit for future generations?

As a starting point, we might want to give more thought to what sort of world we would wish to see in the future. For example, we might imagine a future where cities

- adequately house their population

- foster economic activity

- create a sensory space in which to live and work

- work in harmony with nature

- are resilient to natural and man-made disasters

- foster social justice.

So how might we achieve this? In an industry that has been slow to adopt modern technologies, technological innovation still offers many important opportunities for creating efficient and effective infrastructure.

Building information modelling offers a radical new platform for delivering infrastructure in a more integrated way. Modern materials can open doors to more energy-efficient infrastructure and smaller environmental footprints. Smart sensors, artificial intelligence and the 'internet of things' could provide flexible infrastructure that can adapt in real time to its users' needs, and detect and repair its own defects.

But technical innovation alone will not deliver the infrastructure that the world needs. We need a much more radical approach, looking afresh at the issues of resilience, adaptability and availability.

Resilience is important because much of our existing infrastructure will not be able to cope with the demands of population growth and climate change. We will need to embrace radical concepts such as floating cities to deal with sea level rise (Figure 5), and vertical rain gardens to manage water resources and urban ecology.

As ICE's State of the Nation: Infrastructure 2014 report argues, it is probably unrealistic to expect future infrastructure to function in extreme conditions (ICE, 2014b). So how do we plan for infrastructure failure and avoid the failure in one area of infrastructure cascading into other areas? Rather than building ever more complex and interdependent systems, might it not be prudent to rely more on local freestanding systems?

Adaptability is required because we cannot be certain about the future. Our infrastructure will have to adapt in real time as future pressures become evident. It will have to adapt as the economy, the climate and communities adapt. Its development will have to accommodate much shorter timescales than is currently the case, to benefit from innovation as and when it arises. And it will need to accommodate environmental pressures better.

Availability is vital because infrastructure should be available to all. Lack of appropriate infrastructure is one of the most divisive factors of modern society. It divides rich from poor and sets apart the developing world from the developed (Figure 6).

We do not need to go far from our 


\section{PRESIDENTIAL ADDRESS:DAVID BALMFORTH}

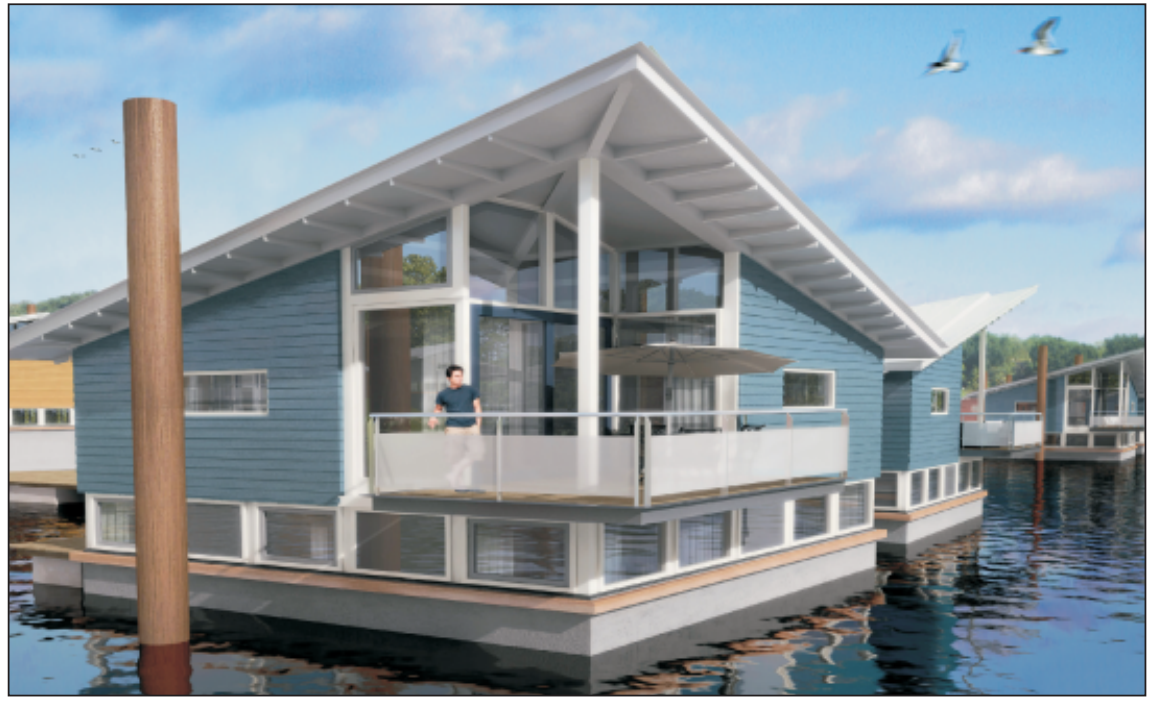

Figure 5. Adaptable infrastructure - floating communities at Maasplassen in the Netherlands (courtesy Chris Zevenbergen)

doorstep to understand this. When we look at the recent flooding events we see that it is the poorer communities, often in our ageing city centres, who suffer most, and who have the fewest resources to help them recover. The better off and the better educated are often more adept at getting their voice heard.

\section{Civil engineers: rising to the challenge}

So how might today's civil engineers rise to the global challenges we face? It is unlikely that this will be through 'business as usual', nor will it be by going it alone. I would like to suggest three areas where we might do things differently.

First, as a profession we might want to ask to what extent could we become truly international - with a vision that our principles and practices are shared by all civil engineers around the world. Could we become the catalyst for change by working with other professions to set out a plan for future cities and global infrastructure? And how might we achieve a shared view, and a shared plan?

Could we work with other stakeholders and the public in a much more integrated way, and in so doing better understand the importance of cultural difference? Could we work in partnership with communities, using their language and values, their timescales, and their priorities? This is not something new - but I am not convinced that this is sufficiently embedded in our way of doing business just yet. It will be important for the future, both in the developing and the developed world.

Second, might we consider focusing more on the benefits our projects bring and not simply on the projects themselves? In the past we have rightly been criticised for a failure to deliver projects on time and budget. Our focus on this has shown some remarkable improvement - High Speed 1, the London 2012 Olympic and Paralympic Games, and Crossrail - demonstrating our ability to deliver to time and budget. The new Forth Road Bridge - the Queensferry Crossing (http://www.forthbridges.co.uk/queensferry-crossing.html) - will be delivered significantly below budget.

But has this focus on delivering project outputs masked our view of the benefits such projects bring? Civil engineering projects by their very nature are expensive, disruptive, and consume large quantities of energy and resources. They are not automatically welcomed by society.

When we listen to people who have suffered from flooding, the misery they face is all too clear. They are afraid to go on holiday in case it rains while they are away. If it rains at night they have to get out of bed to see if their home has flooded. They do not lead normal lives.

When we deliver flood alleviation schemes we do not simply cross off the number of properties on a flooding register - we transform peoples' lives. If we set out more clearly the long-term benefits that civil engineering projects bring, then society might more easily recognise their value. Might this then help us to regain the moral high ground in the infrastructure debate?

Third, I would like to see a drive to unblock the barriers to innovation.

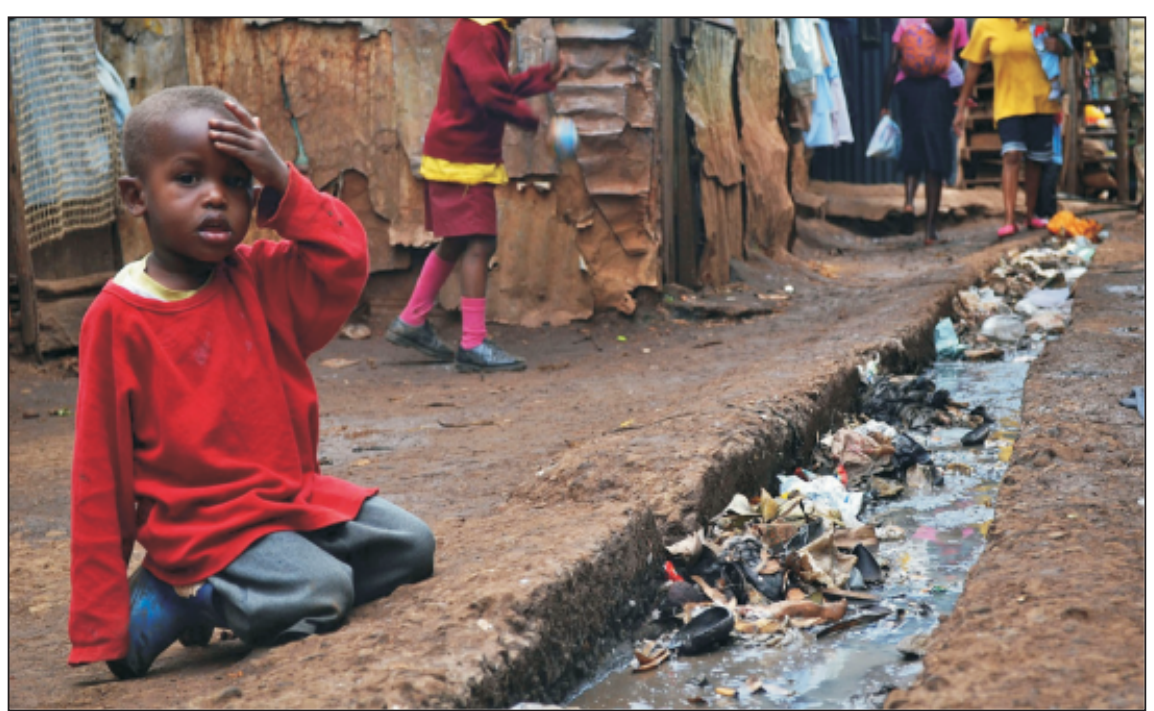

Figure 6. Unavailable infrastructure - lack of adequate water and sanitation in the developing world 
Innovation, by definition, is a way of doing things differently - which means it encapsulates uncertainty and the chance of failure. A culture that welcomes new ideas, accommodates failure and celebrates success will foster innovation.

We have an opportunity to make this part of our day-to-day work, not just the occasional success. Might we not create contractual arrangements that incentivise innovation, where liability is shared equitably with those who will benefit from the innovation, and where this is reflected in our means of insurance?

\section{Changing ICE}

We cannot expect to bring about the necessary change unless ICE itself also changes. In a rapidly moving world ICE needs to be more agile and adaptable in the way that it supports the work of practising civil engineers, to make it relevant, enabling and diverse.

Relevant means making a real difference to how civil engineers are supported on a day-to- day basis. It means enabling knowledge sharing and access to experts in real time from the workplace; producing standards and codes of practice that are flexible rather than restrictive; and influencing the world's decision makers through timely, informed and independent advice.

Enabling means developing a workforce that is more flexible, adaptable and highly skilled. It means developing qualifications that are mutually recognised; valuing skills developed in the workplace as much as through academic learning; and recognising the value of lifelong learning.

Diverse means benefitting from the experience that comes from diverse groups with a good mix of age, gender, ethnicity and experience. We may sign up to policies on diversity but do we really understand what it takes to foster diverse organisations - where diversity is welcomed rather than merely tolerated? Diverse teams have been shown to be more productive, more innovative and happier places to work.

In 2015 ICE will set out a new framework for qualification and membership that recognises the growing breadth of civil engineering and the importance of lifelong learning. As part of ICE's 'Shaping the World' initiative (http://shapingtheworld.org.uk/), it will organise a global conference targeted at the leaders of the world's cities that face the most serious challenges for the future. ICE will use this to help shape their future plans, distil the key lessons from global research and influence the political landscape internationally.

ICE will ensure the future of the profession by working more actively with our fellow engineering professions, and the 'Tomorrow's Engineers' programme in particular (http://www.

tomorrowsengineers.org.uk/), to deliver a step change to the way we inspire young people.

Also in 2015 ICE will launch its new web site. This will improve navigation and overall user experience - but more importantly it will give better connectivity to ICE's training programmes and knowledge services so that it can make a real difference to the work of civil engineers on a day-to-day basis.

All of this will begin a process of shaping ICE so that it is fit for the future.

\section{Fit for the future}

That nicely brings me back to my starting point, to ask if the challenges we face today really are that different from those faced by Telford and his colleagues when they set out on a journey that transformed society. Is our future any less certain than theirs? Is our threshold of change any more difficult than theirs? Are our opportunities any less than theirs? I suspect not.

Over the generations we have shaped a truly remarkable profession. It has proven, time and again, able to respond to the demands of society. I am confident that we will prove ourselves, and our profession, fit for the future. Because we all know what it is we have to do, we will have the skills and capability to do it, but most of all, we genuinely believe that it is our job to make a difference.

\section{References}

BBC (2005) http://news.bbc.co.uk/1/shared/spl/hi/ americas/05/katrina/html/ (accessed 05/12/ 2014)

Bloomberg (2013) Shanghai glut rises with tallest tower: real estate. Bloomberg News, 17
December. See http://www.bloomberg.com/ news/2013-12-16/shangai-glut-rises-withtallest-tower-real-estate.html (accessed 17/12/2014).

Gregory J (2013) Projections of sea level rise. Climate Change 2013: The Physical Science Basis. Working Group 1 Contribution to the IPCC Fifth Assessment Report.

Intergovernmental Panel on Climate Change, Geneva, Switzerland. See http://www.ipcc.ch/ pdf/unfccc/cop19/3_gregory13sbsta.pdf (accessed 05/12/2014).

ICE (Institution of Civil Engineers) (2014a) http:// www.ice.org.uk/About-ICE/Our-history (accessed 05/12/2014).

ICE (2014b) State of the Nation: Infrastructure 2014. ICE, London, UK. See http:// www.ice.org.uk/State-of-the-Nation (accessed 05/12/2014).

IPCC (Intergovernmental Panel on Climate Change) (2007) Climate Change 2007: Synthesis Report. Contribution of Working Groups I, II and III to the Fourth Assessment Report of the Intergovernmental Panel on Climate Change (Core Writing Team, Pachauri RK and Reisinger A (eds.)). IPCC, Geneva, Switzerland. See http://www.ipcc.ch/pdf/ assessment-report/ar4/syr/ ar4_syr_full_report.pdf (accessed 05/12/2014).

Mayor of London (2011) Securing London's Water Future - the Mayor's Water Strategy. Greater London Authority, London, UK. See http://www.london.gov.uk/sites/default/files/ water-strategy-oct11.pdf (accessed 05/12/ 2014).

NYISO (New York Independent System Operator) (2014) Power Trends 2014: Evolution of the Grid. NYISO, Rensselaer, NY, USA

ONS (Office of National Statistics) (2014) Regional Gross Value Added Highest in London in 2012. ONS, Newport, UK. See http://www.ons.gov.uk/ons/rel/regionalaccounts/regional-gross-value-added-incomeapproach-/december-2013/sty-regional-gva2012.html (accessed 05/12/2014).

Rafferty JP (2014) Christchurch earthquakes of 2010-11. In Encyclopaedia Britannica. See http://www.britannica.com/EBchecked/topic/ 1759509/Christchurch-earthquakes-of-201011 (accessed 05/12/2014).

Tokyo Metro (2014) Business Situation. Tokyo Metro, Tokyo, Japan. See http:// www.tokyometro.jp./en/corporate/enterprise/ transportation/conditions/index.html (accessed 17/12/2014).

United Nations Department of Economic and Social Affairs, Population Division (2014) World Urbanization Prospects: The 2014 Revision, Highlights. United Nations, New York, NY, USA. See http://esa.un.org/unpd/ wup/Highlights/WUP2014-Highlights.pdf (accessed 05/12/2014).

\section{What do you think?}

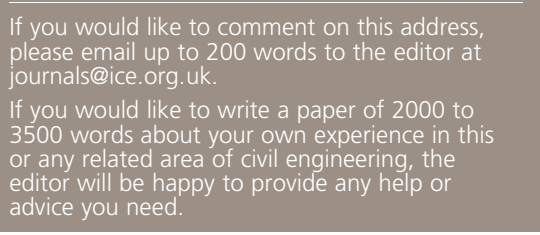

